\title{
Consciousness as Presence: An Exploration of the Illusion of Self
}

\author{
Charles KedRic FinK \\ Miami Dade College \\ cfink@mdc.edu
}

\begin{abstract}
Buddhism teaches that 'self' as a substantial, enduring entity is an illusion. But for self to be an illusion there must be something in our experience that is misinterpreted as self. What is this? The notion of an experiential self plays an important role in phenomenological investigations of conscious experience. Does the illusion of self consist in mistaking a purely experiential self for a substantial self? I argue against this and locate the source of the illusion in time-consciousness. It is the essence of consciousness to flow, but the flow of consciousness presupposes an experiential present. The experiential present - an abiding sense of 'now' - is the dimension through which experiences are experienced as streaming. It is this, I argue, that is misinterpreted as an enduring self. I support my account by arguing that the synchronic and diachronic unity of consciousness can be accounted for in terms of impersonal, temporal experience, and that conceiving of consciousness as the presence-dimension rather than as the I-dimension affords a solution to the brain-bisection puzzle.
\end{abstract}

Keywords

non-self, self-identity, self-luminosity, time-consciousness, brain-bisection puzzle

\section{INTRODUCTION}

A mirage is an appearance but not necessarily an illusion. The reality of a mirage is that it is an appearance. A mirage is exactly as it appears to be, but nothing more. It is illusory only if it is misapprehended as a distant body of water. According to Buddhism, self is illusory in the same sense. An illusion is a mistaken cognition. I conceive of myself as a being that exists over time while undergoing 
various physical and psychological changes. This is an illusion because there is no enduring being that undergoes these changes. But for self to be an illusion, there must be something that is misapprehended as self. What is this? What is it that underlies the illusion of self?

The answer may seem obvious. What I misconceive as self is a person - specifically, the person writing these words. In Buddhism, a person (puggala) is understood to be a composite being, a collection of five 'aggregates' (khandhas). A key reason why self is illusory is because no composite thing is irreducibly real. A house, for example, is a composite thing; it is nothing over and above the parts comprising it. These parts are conceptually grasped together as a 'house', but the house does not exist independently of its conceptualization as a house. Analogously, a person's body (rūpa) is conceptually constructed:

Friends, just as when a space is enclosed by timber and creepers, grass, and clay, it comes to be termed just 'house', so too, when a space is enclosed by bones and sinews, flesh and skin, it comes to be termed just 'material form' (rüpa). (MN I 190)

A person's body is only conventionally, not ultimately, real. And the same analysis applies to a person as a whole. A person is composed of various component processes (including a body) and is conceptually grasped into being as a person. Another passage from the canonical literature compares a person to a chariot:

Just as, with an assemblage of parts,

The word 'chariot' is used,

So, when the aggregates exist,

There is the convention 'a being'. (SN I 135)

Like a chariot, a person is only conventionally or nominally real, and the illusion of self consists in mistaking this nominal reality for something that is ultimately real.

But this is not the illusion of self, or at least not the heart of it. Whether or not the person writing these words is irreducibly real, he still conceives of himself as me. Self is illusory, not because there is here-now the misconceiving of a particular person as a self, but because there is here-now the misconceiving of this person as myself. This is the 'sense of self' - the 'conceit of "I am"' (asmiti māna) - that needs to be explicated. In this paper, I argue that what underlies the illusion of self is the experiential present, an abiding sense of 'now'. It is this, I argue, that is the phenomenological core of the sense of self. The illusion of self consists in misapprehending the impersonal 'now' as the personal 'I'.

\section{THE EXPERIENTIAL SELF}

I can imagine that I lived before. I can imagine, for example, that I was once a slave in ancient Greece. The life I would have lived in ancient Greece would have been quite different from my present life. Still, there would have been something that these two lives shared in common. They both would have been experienced as my lives. According to the phenomenological tradition, whether or not there is some 'thing' that is me, there is a continuous thread that runs through the fabric of my conscious life, and this is that it is experienced as my life. This sense of ownership or 'mineness' characterizes my conscious life and every experience belonging to it. When I listen to music, or taste an apple, or see a sunset, there is not an impersonal listening, tasting, or seeing; rather, there is something that it 
is like for me to be listening, tasting, or seeing. If this is correct, then whether or not there is a substantial self, there is an experiential self. When I imagine being a Greek slave, for example, I imagine experiencing myself as this person, just as I now experience myself as the person writing these words. But these are different people. If I could have been a Greek slave, then it cannot be that I am the person writing these words. It cannot be that this person might have been that person. Although I experience this person as me, this person is not me.

This is one way of understanding the illusion of self, and not only is it consistent with the notion of an experiential self, it presupposes it. An illusion is a mistaken cognition. For self to be an illusion, there must be something in my experience that is misinterpreted; that is, there must be an experiential self. The illusion consists in the fact that this experiential self is misinterpreted as a substantial self. I identify myself with a being in the world - with the person writing these words, or with this person's brain, or with this person's immaterial mind or immortal soul. This is the illusion. This person's experiences are experienced as mine, and this is indistinguishable from experiencing this person as me. In reality, though, there is nothing in the world that is me, that is, there is nothing in the world that is a substantial I-identity.

Seen in this way, the illusion of self is a special case of a more general illusion. A fundamental tenet of Buddhism is that all conditioned phenomena are impermanent (anicca) and, therefore, insubstantial or 'non-self' (anattā). In the Anattalakkhana Sutta (SN 22:59), the Buddha asks: 'What do you think, bhikkhus, is form permanent or impermanent?' The answer, of course, is 'impermanent'. He raises the same question with regard to all the constituents of a person the five khandhas - and the answer is the same in each case. No substantial self can be found, because there is no constituent of a person that is unchanging or permanent. In the Chachakka Sutta (MN 148), we encounter a similar argument:

If anyone says, 'The body is self', that is not tenable. The rise and fall of the body are discerned, and since its rise and fall are discerned, it would follow: 'My self rises and falls'. That is why it is not tenable for anyone to say, 'The body is self. Thus the body is non-self. (MN III 283)

The same argument is applied to every possible candidate for a self, such that it is said 'all dhammas (everything) is non-self' (AN I 286). There is no self because there is no substantial being that underlies the cycles of rising and falling, of coming into being and passing away.

A substantial being is something that endures throughout the cycles of change. But if everything at every moment is in the process of coming to be (rising) or ceasing to be (falling), there is no time when something simply is. There are no beings but only 'becomings'. The doctrine of impermanence implies that there is literally nothing to grasp, nothing to cling to, if 'even for a mere finger snap' (AN I 35). There is a process of becoming by which a living thing grows and matures $-\mathrm{a}$ process by which a tree comes into being from a seed, for example, or an animal from a zygote - and there is a reverse process by which any living thing ages, dies, and decays. There is a process of becoming by which a manufactured object - a table, a chair, a house, a painting - is created, and a reverse process by which it is destroyed. And even when something 'is' it continuously changes. 'Bhikkhus, there are these three characteristics that define the conditioned. What three? An arising is seen, a vanishing is seen, and its alteration while it persists is seen' 
(AN III 152). But, strictly speaking, no 'thing' arises or vanishes, no 'thing' persists while undergoing alteration; what we conceptualize as an enduring entity (as something to cling to) is, in reality, a continuous transformational process.

The general illusion, then, consists in mistaking continuities for persistent identities. In the process of coming to be, an infant arises from a fetus, an adolescent from an infant, and an adult from an adolescent. And no sooner does a person 'come to be' than the process of ceasing to be begins. A middle-aged person comes into being from the matured adult, an elderly person from the middle-aged person, and a corpse from the elderly person. ${ }^{1}$ The corpse itself passes through various stages of decomposition, from 'bloated, livid, and oozing matter' to bones 'rotted and crumbled to dust' (MN I 58, 58-59). Each stage in this transformational process arises from or is causally dependent upon a previous stage and is continuous with it, but there is no identity that is preserved in this process, no self that comes to be or ceases to be. Of course, there is a sense in which a man of sixty is the 'same' person as the boy he remembers having been. But, as Francis Story comments,

he is the 'same' person only in a conventional sense. Actually, there is no single item of his psycho-physical complex that is the same as it was when he was a boy. In terms of what actually exists it can only be said that the man of sixty belongs to the same line of causal continuity as did the boy that he remembers having been: he is the end product of an infinite series of connecting states of being - or rather, of coming-to-be - which make up his individual world-line. $(2000,17)$

In the same way, a stream of consciousness (viññana-sota) is a process, and each moment of consciousness arises from a previous moment; each stage in the process is dependent upon a previous stage and is continuous with it. It is this, according to Buddhism, that accounts for the phenomenon of rebirth or 'rebecoming' (punabbhava). There is no 'thing', no inner essence or soul, that passes from one lifetime to the next; rather, one person $A$ is 'reborn as' another person $B$ because the first moment of B's conscious life arises from the last moment of A's conscious life - 'arises from' in the same sense in which each moment of A's conscious life arises from (is causally conditioned by) the immediately preceding moment.

\section{THE RADICAL CONTINGENCY OF SELF}

This is a plausible account of the continuity of consciousness, and it is not unlike other philosophical treatments of the issue. But it is a metaphysical or thirdpersonal account, not a phenomenological or first-personal account. It may be that each stage in my conscious life is causally dependent upon a previous stage, but this does not explain the continuity of consciousness as I live and experience it. There is 'something that it is like' to experience myself as a being that exists over time, and this is not accounted for in terms of causal continuity. To make a comparison, there is causal process by which I experience certain things as red

1. I here describe the processes of coming to be and ceasing to be in terms of conventionally recognized stages - a fetus, an infant, an adult, a middle-aged person, and so on - but it should be understood that there is no substantial being that corresponds to any of these stages. What we recognize as an 'adult', for example, is simply a stage in a transformational process. Abhidhamma metaphysics represents this process, at its most basic level, as an integrated series of discrete momentary events (called dhammas).

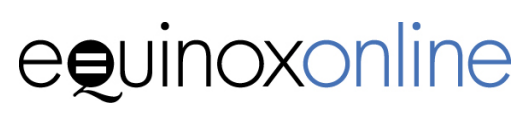


- a process involving the molecular properties of these objects, wavelengths of light, my retinas, my optic nerves, and my visual cortex. But there is a difference between explaining this causal process and accounting for what it is like to experience something as red. In the same way, it may be that there is a causal process by which I experience myself as a being that exists over time, but this does not account for what this experience is like. If the illusion of self consists in mistaking an experiential self for a substantial self, then what accounts for the sensed continuity of consciousness, my awareness of myself over time, is the sense of 'me' and 'mine'. Whatever past experiences belong to my conscious stream were experienced as mine (or experienced first-personally), and whatever future experiences belong to this stream will be experienced as mine. Phenomenologically, it is this qualitative feature of conscious experience, its first-personal nature or mineness, that explains the continuity of consciousness.

But what explains the sense of 'me' and 'mine'? My conscious life is the conscious life of a particular person, but this is not what makes it my conscious life; rather, what makes this particular person me is the fact that this person's conscious life is mine. My experience of myself is not simply this person's experience of himself because (1) this person might have experienced himself as someone else, and (2) I might have experienced myself as someone else. While it is a necessary fact that this person is this person, it is a contingent fact that I am this person, and this fact is not explicable in terms of other facts about this person. Erich Klawonn refers to this, suggestively, as the 'incarnational contingency' of the 'I-dimension' $(2009,80)$. The causal account of conscious continuity may correctly explain how it is that my sense of self is transmitted over time, or why it is that I experience myself as the same person throughout this person's life, but it does not explain why I experience myself as this person to begin with. Put differently, the causal account may explain why this person experiences himself as himself from one moment to the next, but it does not explain why this person ever experiences himself as me. As Klawonn argues, 'My being the person that I am and nobody else, is not logically implied by any set of data about the person whose mental life happens to be present "in" the I-dimension. I just happen to be whoever I am' $(2009,80)$.

Let us consider how the above two claims might be defended. ${ }^{2}$ (1) Suppose that the blastocyst from which the person I happen to be had split, resulting in the birth of a pair of twins. It is an open question as to whether I would have existed in this case. But there are apparently no facts about the situation that could explain why I would or would not have existed. Given that both twins would have come into being from the very same blastocyst from which I came into being, and given that both would contain exactly the same genetic material, why would I not exist? But if I did exist, given that both twins would have an equal claim to be me, nothing would explain the fact that I was one twin rather than the other (on which, see, further, note 7). In the first case, nothing would explain the fact that I didn't exist. In the second, nothing would explain the fact that I did - that I was this twin rather than that one. There is apparently nothing about the person I happen to be, the person who is writing these words, that explains the fact that this person is me. It might have happened that this person was no more me than

2. For a much fuller defense of these claims, see Fink 2012, 295-300. 
my twin brother (if I had one) was me. My twin brother would have experienced himself as someone, but he would not have experienced himself as me (or not the same 'me' as me). I experience myself as the person writing these words, but this person didn't have to experience himself as me.

(2) Consider the apparent fact that out of all the people who exist now, or ever have existed, or ever will exist, exactly one of them is the person I take myself to be. This is truly remarkable. It is remarkable because, as argued above, there is nothing about this person that explains why this person is me. And given this, there is no reason to think that I could not have experienced myself as someone else. In fact, there is no reason to think that I have not in the past experienced myself as someone else or that I will not in the future experience myself as someone else. The belief that I am uniquely the person I happen to be has no factual basis at all, because there are no facts about this person that explain why this person is me. Voltaire once remarked that it is no more surprising to be born twice than it is to be born once. If, as Klawonn says, I just happen to be the person I am, then it is indeed a surprising fact that I exist - in fact, astonishing. But if there is nothing unique about this person that explains the fact that he experiences himself as me, then there is no reason to think that this is a unique experience; that is, there is no reason to think that no one else in the past has ever experienced himself (or herself) as me (the same 'me' as the 'me' I currently take myself to be) or that no one else in the future will ever have this experience. Of course, there is no reason to think that this does occur repeatedly, but by the same token there is no reason to think that it occurs only once. Both possibilities seem equally likely, or equally unlikely.

The existence of the person writing these words is a contingent fact, but unlike the existence of this person, my existence is a radically contingent fact in the sense that nothing explains it. This is one respect in which self-identity differs from personal identity. There is an explanation of why it is that this person exists - an explanation involving the existence of a particular spermatozoon and a particular ovum or the genetic material contained therein - but there is no explanation of why it is that I exist (of why it is that anyone ever experiences himself or herself as me) because there are no facts that explain why anyone is me. The fact that I exist might be compared to another inexplicable fact: the fact that a world exists. There is no fact more basic than the fact that a world exists, and hence there are no other, more basic facts in terms of which it is explicable. The fact that there is something rather than nothing, like the fact that I exist, is a radically contingent fact. There just happens to exist a world, and I just happen to exist.

The fact that I exist, like the fact that a world exists, is utterly mysterious. But maybe the riddle of my first-personal existence is a riddle only because of how I conceive of myself. Understood in one way, the illusion of self consists in mistaking a purely experiential self for a substantial self. But maybe there is a deeper, more fundamental illusion. Maybe the deepest illusion is taking the experiential self to be a 'self rather than a strictly impersonal feature of conscious awareness.

\section{THE SELF-LUMINOSITY OF CONSCIOUSNESS}

The metaphor of 'illumination' plays an important role in classical Indian phenomenology. 'Luminous, bhikkhus, is this mind, but it is defiled by adventitious

3. Some theorists - referred to as 'other-illumination' theorists - held that experiences become

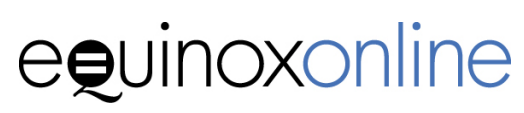


defilements. Luminous, bhikkhus, is this mind, and it is freed from adventitious defilements' (AN I 10). Consciousness has the quality of radiance (pabhā). Like a lamp, consciousness illuminates the world; it is the essence of consciousness to make things appear. And like a lamp, not only does consciousness illuminate the world, it illuminates itself. It is self-illuminating. But the self-luminosity of consciousness can be understood in two, importantly different ways. Understood egologically, it means that to consciously experience anything is to experience it as one's own experience. Consciousness is essentially first-personal, whether or not this involves a substantial self or ego. Understood non-egologically, consciousness is self-luminous in the sense that every conscious experience is simultaneously aware of itself (though this is not understood as a higher-level or transitive awareness). In this view, as Dan Zahavi expresses it, self-awareness is understood 'as the acquaintance that consciousness has with itself and not as an awareness of the experiencing self' $(2005,100)$.

Both views are represented in the Buddhist tradition. Dharmakirti, the seventhcentury Yogācārin philosopher, gave an egological account of self-luminosity (svasamvedana), arguing that consciousness is inherently first-personal. But, he argued, this feature of conscious awareness does not contradict Buddhist teaching. Unlike a substantial self, self-luminosity is purely formal or experiential. It is, as Joel Krueger describes it, 'the phenomenally continuous, first-person perspective one has on the stream of one's own experience. It is a feature of the stream of experience, and not a self standing behind the experience' $(2011,33)$. The perspectival self, as a purely formal dimension of conscious experience, might be compared to a spatial perspective in visual experience (cf. Searle 2004, 204). Whatever is seen is seen from a spatial point of view, but a spatial point of view is nothing in itself. In the same way, whatever is experienced is experienced from a personal point of view, but a personal point of view is nothing in itself; like a spatial perspective, the first-person perspective is a structural feature of conscious awareness and nothing more.

In Dzogchen, on the other hand, self-luminosity is understood impersonally. It refers, in Sogyal Rinpoche's words, to 'the sky-like nature of our mind', a dimension through which experiences flow like passing clouds, 'a primordial, pure, pristine awareness that is at once intelligent, cognizant, radiant, and always awake' $(2002,48)$. Whereas, for Dharmakirti, self-luminosity is a feature of the experiential stream and, as such, is 'dependently conditioned by the continually changing interplay of successive contents' (Krueger 2011,33), in Dzogchen self-luminosity situates consciousness (or direct awareness, Skt vidyā, Tib Rig pa) outside the realm of conditioned, worldly phenomena. In the Mahāyana Uttaratantra Śāstra (a text from the tathagatagarbha literature that inspired Dzogchen), we read:

The nature of mind as the element of space

does not [depend upon] causes or conditions,

nor does it [depend on] a gathering of these.

It has neither arising, cessation, nor abiding.

conscious when they are the objects of a higher-order introspective awareness. Other theorists - 'self-illumination' theorists - believed that every cognition is reflexively self-aware. Here I focus on the second school of thought, which also represents the mainstream view in modern Western phenomenology. For discussion of these contrasting views, see Siderits et al. (2011, 9-11). 
This clear and luminous nature of mind is as changeless as space. It is not afflicted by desire and so on, the adventitious stains, which are sprung from incorrect thoughts.

(Gyamtso and Fuchs 2000, 27)

Consciousness is not a worldly phenomenon because, unlike worldly phenomena, it is unconditioned: it 'does not [depend upon] causes or conditions'. It is the dimension or 'space' in which worldly phenomena make their appearance.

Situating consciousness outside the phenomenal realm might seem to contradict the Buddha's teaching on Dependent Origination. In the Mahātanh āsankhaya Sutta (MN 38), the Buddha emphasized that consciousness (viñnāna) is 'dependently arisen' and that 'without a condition there is no origination of consciousness'. But here and elsewhere the Buddha's teaching seems to be that every specific form of consciousness dependently arises. In the same sutta, we read:

When consciousness arises dependent on the eye and forms, it is reckoned as eyeconsciousness; when consciousness arises dependent on the ear and sounds, it is reckoned as ear-consciousness; ... when consciousness arises dependent on the mind and mind-objects, it is reckoned as mind-consciousness. (MN I 259)

But this does not mean that consciousness itself is a dependent, conditioned phenomenon. Indeed, if the essence of consciousness is luminosity, and if consciousness is essentially self-luminous, this implies that consciousness does not depend upon worldly causes or conditions; consciousness illuminates itself independently of any conditioning factors. Because consciousness is unconditionally luminous, the unconditioned nature of consciousness is pure, self-luminous awareness. Precisely this line of thought has been developed by Dzogchen teachers. Nyoshul Khenpo Rinpoche once wrote:

Profound and tranquil, free from complexity

Uncompounded luminous clarity,

Beyond the mind of conceptual ideas;

This is the depth of the mind of the Victorious Ones.

In this there is not a thing to be removed

Nor anything that needs to be added.

It is merely the immaculate

Looking naturally at itself.

(Quoted in Rinpoche 2002, 50)

Nibbāna is unconditioned. Hence, the mind of the 'Victorious Ones' - those who have crossed over into final Nibbāna - is unconditioned; it is pure ('immaculate'), self-luminous ('Looking naturally at itself') awareness. We might note that a similar point (concerning the unconditioned nature of the enlightened mind) is made in the Alagaddūpama Sutta (MN 22), where the Buddha describes the consciousness of a bhikkhu who has 'cut off at the root' the "conceit of "I am"':

Bhikkhus, when the gods with Indra, with Brahmā, and with Pajāpati seek a bhikkhu who is thus liberated in mind, they do not find [anything of which they could say]: 'The consciousness of one thus gone is supported by this'. Why is that? One thus gone, I say, is untraceable here and now. (MN I 140)

There is also the following cryptic verse from the Brahmanimantanika Sutta (MN 49) in which the Buddha describes the meditative experience of Nibbāna: 
Consciousness non-manifesting,

Boundless, luminous all-around. (MN I 290)

Commenting on this verse, Bhikkhu Bodhi writes that 'this meditative experience does not make manifest any conditioned phenomena of the world and thus may be truly described as "non-manifesting"” (Ñānamoli and Bodhi 2009, 1250). Unlike other forms of consciousness, which arise from contact with worldly phenomena, the meditative experience of Nibbāna arises only when consciousness is liberated from all conditioning factors. This is why Nibbāna is 'the unageing, unailing, deathless, sorrowless, and undefiled supreme security from bondage' (MN I 163). The unconditioned nature of consciousness, revealed in the meditative experience of Nibbāna, is pure awareness, 'Boundless, luminous all-around'. ${ }^{4}$

\section{CONSCIOUSNESS AS PRESENCE}

Phenomenologically, how might we distinguish between these two views - the egological (personalist) and the non-egological (impersonalist) conception of self-luminosity? Perhaps the difference has to do with whether there is something that remains invariant throughout the course of a conscious life. For the impersonalist, each experience is aware of itself and is in this sense self-illuminating. While this is so, there is no continuous self, not even an experiential one. Each experience is unique, and so each episode of self-awareness is unique. There is, or so it would seem, no experiential constant in the conscious flow. For the personalist, on the other hand, there is an experiential constant in the series of conscious states, something that remains the same, and this is a unique sense of 'me' and 'mine'.

In the Theravāda tradition, the selfless or impersonal nature of experience is confirmed through meditative practice (specifically, insight or vipassanā meditation). As Henepola Gunaratana explains:

With mindfulness one sees all phenomena without reference to concepts like 'me', 'my', or 'mine'. For example, suppose there is a pain in your left leg. Ordinarily consciousness would say, 'I have a pain'. Using mindfulness, one would simply note the sensation as a sensation. One would not tack on the extra concept 'I'. $(1992,152)$

Bhikkhu Bodhi writes:

The Buddha teaches that the craving and clinging that hold us in bondage are sustained by a network of 'conceivings' (maññita) - deluded views, conceits, and suppositions that the mind fabricates by an internal process of mental commentary. ... The task of insight meditation is to sever our attachments by enabling us to pierce through this net of conceptual projections in order to see things as they really are. (Ñānamoli and Bodhi 2009, 39-40)

According to these commentators, 'self' is a conceptual construction. There is the conceptualization of myself as a unitary being that exists over time, and this selfconcept is embedded in various past-directed and future-directed psychological states. I cannot remember yesterday's events, or have regrets, or mourn some loss, or hold grudges without conceptually projecting 'myself' into the past. I cannot anticipate my retirement, or plan a vacation, or hope to learn French, or worry about meeting my bills without conceptually projecting 'myself into the

4. This meditative experience also reveals the nature of final Nibbanna when consciousness is permanently liberated from all conditioning factors.

\section{eevinoxonline}


future. Just as I conceive (or misconceive) of things in the world, not as continuous processes, but as enduring entities, I conceive of 'myself' in the same way.

Yet it is clear that I do not simply conceptualize myself as a being that exists over time; I also experience myself in this way. If I sit in meditation and follow my breath, I am not reflecting upon the past or anticipating the future. I am not conceptually connecting my present experience with any past or future experience. My consciousness is confined to what is immediately present. And what I experience when I anchor my awareness in the present moment is the continuity of consciousness at its most basic or primitive level. What I experience is the flow of time. Even if I altogether lacked the conceptual resources to project myself into the past or the future, so long as I was conscious, I would experience the flow of time. Consciousness is never static; it is essentially dynamic; it is the essence of consciousness to flow. And the conceptually constructed self has nothing to do with the moment-by-moment fluidity or continuity of lived experience. The moment-by-moment continuity of consciousness is its temporal continuity.

This, I believe, is the key to unlocking the sense of self. Consciousness is essentially luminous. Like a beam of light illuminating a train passing in the night, consciousness illuminates a passing stream of experiential phenomena. Things appear, as if out of nothing, pass through this area of illumination and slip from view. It is the essence of consciousness to make things appear. But things appear only in the present moment. The appearing of things is their 'presencing'. Metaphysically, becoming is the cyclical process of coming to be and ceasing to be, of arising and passing away. But experientially, it is the process of coming to be present and ceasing to be present, of appearing and disappearing; it is a process forever flowing through the now. If it is consciousness that makes things appear, and if the appearing of things is their 'presencing', then it is consciousness that 'presences' the world. This abiding sense of presence, this area of illumination through which phenomena stream, is, I believe, the essence of the sense of self.

Wolfgang Fasching (2009) makes a similar observation. 'My suggestion', he writes, "is that "the I" has to be conceived of as having the character of a dimension with regard to its experiences', (146) and he specifically equates the 'I' with consciousness. Consciousness is the dimension of phenomenal appearance $-\mathrm{a}$ dimension through which 'experiences are exclusively present as streaming' (144). He writes:

Each 'now' I am aware of is only there for me as passing by, in its transition to the 'no-longer-now' (for a moment is not now present and then elapses later on; rather, the very essence of the present is temporal transition, and it is precisely as such that it is present to us). ... There is no givenness of a now except as passing. (145)

This is true with regard to the contents of consciousness, but not with regard to consciousness itself. If each now is present only as passing, if the passage of time consists of the ever-changing now, what is it with respect to which the now changes and time passes? To make sense of the passage of time, at least as we experience it, we must suppose that there is an invariable conscious structure, a fixed reference point, with respect to which time passes. That is, there must be an invariable, experiential present. I am suggesting that the experiential present is not just a structural feature of consciousness, but consciousness itself. Consciousness is the presence-dimension. 
We are now in a position to expose the deeper, more fundamental illusion that is the sense of self. Fasching says, and I agree (up to a point), that

I am my consciousness, and not some entity that has or owns it, but this consciousness is the one experiencing, the one presence as the realm of existence of the many experiential contents (and consequently 'transcendent' with regard to them, whilst not being a result of a synthesis between them). (144)

But why, we must ask, should we call this consciousness my consciousness? Why should a temporal point of view, the standpoint of the experiential present, be equated with a personal point of view, the standpoint of the experiential self? Fasching correctly observes that 'There is no present experience that is not there as streaming', but he immediately adds that it is not an impersonal dimension, the experiential present, through which experiences stream; rather, it is 'the dimension of first-personal presence' that 'abides as the "locus" of passage' (145). This 'dimension of first-personal presentation', he tells us, has 'no other essential property than being me' (146). But why should the 'now' be personalized as the 'me'? If the account I have given is correct, then there is indeed an experiential constant in the flow of consciousness, but this is not an egological dimension. The person writing these words experiences himself as me, but the phenomenological basis for this is the experiential present. The illusion of self is the mistaken cognition that the 'now' is the 'me'.

The notion of an experiential self plays a dual role in understanding consciousness. First, it accounts for the synchronic and diachronic unity of consciousness. What unites simultaneous experiences as organic elements of the same moment of conscious awareness is that they are simultaneously experienced as mine; and what unites consciousness over time is that past, present, and future experiences have been, are, or will be experienced as mine. As Dan Zahavi writes:

Whereas we live through a number of different experiences, the dimension of firstpersonal givenness remains unchanging. It stands, to use a striking image from James, permanently, like a rainbow on a waterfall, its own quality unchanged by the events that stream through it $(2005,67) .^{5}$

But if I am correct, the problem of the synchronic unity of consciousness is misstated. The question is not what binds together different but simultaneous experiences to form a unified moment of conscious awareness; rather, these experiences are bound together precisely because they are experienced as simultaneous. Similarly, the problem of the diachronic unity of consciousness is misstated. The question is not what unifies consciousness over time, because it is time itself that unifies consciousness. What unites my experiences over time is that they flow through the same presence-dimension. Whatever belongs to a given stream of consciousness was, is, or will be experienced in that stream as now. The continuity of consciousness is its temporal continuity, and the experiential constant that underlies this process is the experiential present, not the experiential self.

Second, the notion of an experiential self accounts for the basic difference between one stream of consciousness and another. If you and I are listening to the same music, there is a difference between your listening to the music and my

5. Interestingly, and I think tellingly, Zahavi elsewhere evokes the very same image to illustrate Edmund Husserl's conception of time-consciousness as an 'unchangeable form of presence' (Gallagher and Zahavi 2012, 92). 
listening to the music even if our two experiences are otherwise indistinguishable. My experience is experienced as mine and your experience is experienced as yours. It is the first-personal nature of conscious experience, the sense of 'me' and 'mine', that grounds the distinction between one experiential life and another. But this distinction can also be accounted for in terms of impersonal, temporal experience. Different conscious lives are different rivers of time, and each experience in the temporal flow is experienced as following another. It is not just that one experience does follow another, but that it is experienced as following another. The experience of time is not a succession of experiences but the experience of succession. Thus, even though your experience of something may occur after my experience of something, your experience is not experienced as occurring after mine. Your conscious life is different than mine because your experience of time's flow is different than mine.

\section{THE BRAIN-BISECTION PUZZLE}

As things stand, there would seem to be no basis for choosing between an egological and a non-egological understanding of self-luminosity. Both accounts seem to fit the experiential data. In this section, I build a case for the non-egological view by considering what it is like to have a divided mind.

Research seems to show that a 'split-brain' patient - a patient whose corpus callosum has been surgically severed - does not have a unified conscious life but rather two parallel streams of consciousness. ${ }^{6}$ One split-brain patient reported that, when dressing himself, he sometimes found himself pulling up his pants with one hand while trying to pull them down with the other, or simultaneously buttoning and unbuttoning his jacket with different hands. Another patient reported that one of her hands would sometimes wake her up in the morning with a slap if she overslept (Darling 1996, Ch. 6). Such anomalies (as well as controlled experiments) strongly suggest that a split-brain patient is not really one patient but two. ${ }^{7}$ This raises the question: Which of the two patients, if either one, is the

6. Thomas Nagel (1971) was one of the first philosophers to discuss the research on split-brain patients. For a current, philosophically rigorous discussion of the research, see Bayne (2008). For a more accessible and engaging discussion, see Darling (1996, Ch. 6). It is the brain-bisection puzzle that inspired Derek Parfit's groundbreaking work on the problem of personal identity (cf. Parfit 1971; 1987, 245-248).

7. This is a controversial claim, but what are the options? Either both hemispheres are simultaneously conscious (the 'two-streams' model, endorsed here), or only one hemisphere is conscious (the so-called 'zombie' model), or the two hemispheres are alternatively conscious (the 'switch' model). Defenders of the zombie model argue that consciousness is restricted to the language-generating hemisphere (typically, the left), reducing the minor hemisphere to an unconscious, information-processing system. Bayne (2008) makes a convincing case against the zombie model, which I will not duplicate here except to say that if consciousness presupposes linguistic capacity, this entails, quite implausibly, that pre-linguistic children, aphasics, and non-linguistic animals are unconscious automata. Bayne himself favors the switch model, according to which the two hemispheres of a split-brain patient are not simultaneously but alternatively consciousness. One problem with the switch model concerns exactly how the switch occurs. If we allow for the possibility that the two hemispheres of a split-brain patient might be completely disjoined - and, perhaps, transplanted into different bodies forming two independently functioning human beings - the switch model becomes utterly implausible. Of course, there are no actual cases like this, but the possibility that a single stream of consciousness can divide into two separate streams must be taken seriously, especially by Buddhists. The split-brain paradox is only one way of framing this possibil- 
original patient? There is no reason to suppose that a successful brain bisection kills the patient. But if the original patient does not survive as just one of the two split-brain patients (because both patients have an equal claim to be the original patient) or as both (because one person cannot be two people), how is it possible for someone to survive a brain bisection?

Suppose I have undergone a brain-bisection. Let us grant that I survive the procedure and that there is no reason to think that I survive as just one or the other of my two hemispheric selves. ${ }^{8}$ Somehow I survive as both (at least in the sense that what matters in my continued existence is preserved in both cases). But if the conscious lives of both hemispheric selves are equally my conscious lives, what is it that is me? The answer cannot be that I am the human being I always was, but neither does there appear to be a better answer. If the subject of one of my conscious lives is my left hemisphere and the subject of my other conscious life is my right hemisphere, how could I be both my right and left hemispheric selves? We might even imagine that the two hemispheres are transplanted into two human bodies forming two independent human beings. Clearly, these would be different persons, and just as clearly there would be no one identifiable as me who survived as both.

This reinforces the point that the experiential self should not be equated with a substantial self. Even though 'I' survive the split-brain procedure, there is nothing after the procedure identifiable as me. But, more than this, the brain-bisection puzzle calls into question the notion of an experiential self. If it is the sense of ownership or mineness that explains my experience of existence over time, then both streams of consciousness must simultaneously be experienced as mine, and this is so even though there is nothing that is me. But how is this possible? If the experiences of both hemispheres are simultaneously my experiences, then I am simultaneously aware of what occurs in both hemispheric streams of consciousness. But if this is so, then I do not have a divided consciousness after all, but a unified conscious life. So granting that I do have a divided consciousness, it cannot be that the experiences of both hemispheres are my experiences.

This analysis is bolstered by what Bayne and Chalmers (2003) refer to as the 'phenomenal unity thesis': that the simultaneous phenomenal states of any subject are phenomenally unified. For example, suppose that in one of my hemispheric streams of consciousness there is an awareness of a chill in my right hand while in the other there is an awareness of an itch in my left hand. According to

ity; another involves the doctrine of rebirth. According to the orthodox Buddhist account, conception occurs only "when there is the union of the mother and father, and the mother is in season, and the gandhabha is present' (MN I 266). Bhikkhu Bodhi identifies the gandhabha with 'the stream of consciousness ... coming over from the previous existence and bringing along its total accumulation of kammic tendencies and personality traits' (Ñānamoli and Bodhi 2009, 1234). Now consider the case of identical twins, discussed earlier. The fission that results in identical twins, who certainly have separate streams of consciousness, occurs after conception. Hence, orthodox Buddhists must concede, not only that it is possible that a stream of consciousness can divide into two separate streams, but that this actually occurs. (Editor: though the other possibility is that another stream of consciousness arrives at the time of the split, and that the previously arrived stream stays with only one side of the split brain).

8. My pre-bisection stream of consciousness is causally continuous with both post-bisection streams. 
the phenomenal unity thesis, if there is something that it is like for me to experience the chill and, at the same time, something that it is like for me to experience the itch, then there must be something that it is like for me to experience both the chill and the itch; I must have a unified phenomenal state subsuming both experiences. ${ }^{9}$ But if I have a divided mind, then there is no unified awareness of what occurs in both streams of consciousness. Therefore, it cannot be that there is something that it is like for me to experience the chill and also something that it is like for me to experience the itch; it cannot be, in other words, that both experiences are mine.

These considerations apparently show that mineness, whether or not it is anchored in a substantial self, has nothing to do with my existence over time. But if this is not what matters, what does? The answer must be that I survive as both hemispheric selves - that is, that what matters in my continued existence is preserved by both hemispheric streams of consciousness - because the right sort of relations hold between my pre-bisection conscious life and the conscious lives of my two post-bisection hemispheres. My conscious life flows on but as two separate streams. Crucially, though, it would be incorrect to describe either one of these streams as 'mine' in the sense in which this is understood by the personalist. The continuity of my conscious life is to be accounted for in terms of strictly impersonal relations between the different phases of my mental continuum, and the holding of these relations is all that matters in my continued existence.

According to the standard Buddhist account, my existence over time is to be accounted for in terms of the holding of causal connections between the successive phases of my mental continuum. Thus, 'I' survive as both hemispheric selves because both hemispheric streams of consciousness are causally continuous with my pre-bisection conscious life. But, again, this is a metaphysical or third-personal account of conscious continuity, not a phenomenological or first-personal account. There is something that it is like to experience myself as a being that exists over time, and this must be understood experientially. There is also something that it is like to have a divided mind, and this must be understood experientially too. The problem, for the personalist, is that this cannot be accounted for in terms of the sense of ownership. If both post-bisection streams of consciousness are simultaneously mine then there must be something that it is like for me to be simultaneously aware of what occurs in both streams. But if there is something that it is like for me to be aware of what occurs in both streams, then I do not have a divided mind. Put differently, while there must be something that it is like to have a divided mind, there cannot be something that it is like for me to have a divided mind.

Although we cannot account for what this is like in terms of the sense of ownership, we can account for this in terms of temporal experience. My conscious life before the procedure is temporally continuous with the conscious lives of my two post-bisection hemispheres. What is experienced in each hemispheric stream after the procedure is experienced as occurring after the experiences in my pre-bisection conscious life, and this is the only sense in which 'I' survive as both hemispheres. I have a divided consciousness after the procedure because

9. This is certainly true on a holistic conception of consciousness, according to which individual experiences are not the building blocks of consciousness but rather modifications of a unified phenomenal field. See Bayne and Chalmers (2003, 38-40) and Searle (2004, 95-96, 105-109).

(C) Equinox Publishing Ltd 2013

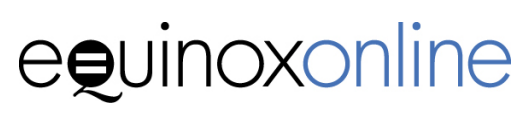


there is no shared experiential present; the simultaneous experiences occurring in these hemispheric streams are not experienced as simultaneous. To clarify this, let us suppose that my last experience before my consciousness divides is a visual impression of the color green. As my consciousness divides, this impression changes into the color yellow in my right-hemispheric stream and into the color blue in my left-hemispheric stream. ${ }^{10}$ To experience change, one event must be experienced as occurring after another. Thus, in my right-hemispheric stream, the experience of yellow is experienced as occurring after the experience of green; whereas in in the left-hemispheric stream, the experience of blue is experienced as occurring after the experience of green. Although the experiences of yellow and blue occur simultaneously, they are not experienced as simultaneous. It is for this reason, and only for this reason, that they belong to separate streams of consciousness.

\section{CONCLUSION}

I have argued that the essence of the sense of self is the sense of presence. The 'self' is the now personalized as the me. An illusion is a mistaken cognition, and it is this mistaken cognition that is the illusion of self. There is an experiential constant in conscious awareness, but this is the experiential present, not the experiential self. I have supported this by arguing that the synchronic and diachronic unity of consciousness can be accounted for in terms of impersonal, temporal experience, and that this account, unlike the personalist view, solves the brain-bisection puzzle.

There is a sense in which 'I' might have lived before - say, as a slave in ancient Greece. If the conscious life of a particular Greek slave is temporally continuous with the conscious life of the person writing these words, then 'I' was once a Greek slave in the same sense in which 'I' was once a child. We can at least imagine how this might be the case. There might be a continuum of experiences such that (1) each of these experiences is experienced as occurring after its predecessor, and (2) one segment of this continuum is the conscious stream of a particular Greek slave and a later segment is the conscious stream of the person writing these words. Beyond this, there is no sense in which 'I' might have been a Greek slave. But this is not what I imagine when I imagine this possibility. When I imagine this, I imagine that I experienced myself as a Greek slave, just as I now experience myself as the person writing these words. But if my account is correct, I never experience myself as anyone. What I cognize as my experiencing myself as someone is, in reality, that person's experience of time. It is this mistaken cognition that is the illusion of self.

\section{ABBREVIATIONS}
AN Anguttara Nikāya
MN Majjhima Nikāya
SN Samyutta Nikāya

10. For the purpose of this illustration, we can imagine that I am operated on (as sometimes occurs in brain procedures) while I am conscious. 


\section{BIBLIOGRAPHY}

Bayne, Tim. 2008. 'The Unity of Consciousness and the Split-Brain Syndrome'. The Journal of Philosophy 105(6): 277-300.

and David Chalmers. 2003. 'What is the Unity of Consciousness?' In The Unity of Consciousness: Binding, Integration and Dissociation, edited by Axel Cleeremans, 23-58. Oxford: Oxford University Press. http://dx.doi.org/10.1093/acprof: oso/9780198508571.003.0002

Bodhi, Bhikkhu, trans. 2000. The Connected Discourses of the Buddha: A Translation of the Samyutta Nikāya. Boston, MA: Wisdom Publications.

, trans. 2012. The Numerical Discourses of the Buddha: A Translation of the Anguttara Nikāya. Boston, MA: Wisdom Publications.

Darling, David. 1996. Zen Physics: The Science of Death, the Logic of Reincarnation. New York: HarperCollins.

Fasching, Wolfgang. 2009. 'The Mineness of Experience'. Continental Philosophy Review 42: 131-148. http://dx.doi.org/10.1007/s11007-009-9107-z

Fink, Charles K. 2012. 'The "Scent" of a Self: Buddhism and the First-Person Perspective'. Asian Philosophy 22(3): 289-306. http://dx.doi.org/10.1080/09552367.2012.709736

Gallagher, Shaun and Dan Zahavi. 2012. The Phenomenological Mind (2nd ed.). London: Routledge.

Gunaratana, Henepola. 1992. Mindfulness in Plain English. Boston, MA: Wisdom Publications.

Gyamtso, K. T. and R. Fuchs. 2000. Buddha Nature: The Mahāyana Uttaratantra Śāstra with Commentary. Ithaca, NY: Snow Lion Publications.

Klawonn, Erich. 2009. Mind and Death: A Metaphysical Investigation. Odense, Denmark: University Press of Southern Denmark.

Krueger, Joel. 2011. 'The Who and the How of Experience'. In Self, No Self? Perspectives from Analytical, Phenomenological, and Indian Traditions, edited by Mark Siderits, Evan Thompson and Dan Zahavi, 27-55. Oxford: Oxford University Press.

Nagel, Thomas. 1971. 'Brain Bisection and the Unity of Consciousness'. Synthese 22: 396-413. http://dx.doi.org/10.1007/BF00413435

Ñānamoli, Bhikkhu and Bhikkhu Bodhi, trans. 2009. The Middle Length Discourses of the Buddha: A Translation of the Majjhima Nikāya (4th ed.). Boston: Wisdom Publications.

Parfit, Derek. 1971. 'Personal Identity'. The Philosophical Review 80(1): 3-27. http://dx.doi. org/10.2307/2184309

1987. Reasons and Persons. Oxford: Clarendon Press.

Rinpoche, Sogyal. 2002. The Tibetan Book of Living and Dying. New York: HarperCollins.

Searle, John. 2004. Mind: A Brief Introduction. Oxford: Oxford University Press.

Siderits, Mark, Evan Thompson and Dan Zahavi. 2011. 'Introduction'. In Self, No Self? Perspectives from Analytical, Phenomenological, and Indian Traditions, edited by Mark Siderits, Evan Thompson and Dan Zahavi, 1-26. Oxford: Oxford University Press.

Story, Francis. 2000. Rebirth as Doctrine and Experience: Essays and Case Studies (2nd ed.). Kandy, Sri Lanka: Buddhist Publication Society.

Zahavi, Dan. 2005. Subjectivity and Selfhood: Investigating the First-Person Perspective. Cambridge, MA: MIT Press. 